\title{
Investigation of Technological University Students' Use of Metacognitive Reading Strategies in First and Second Languages
}

\author{
Yi-Jiun Jou ${ }^{1}$ \\ ${ }^{1}$ Department of Applied Foreign Languages, Cheng Shiu University, Kaohsiung, Taiwan \\ Correspondence: Yi-Jiun Jou, Department of Applied Foreign Languages, Cheng Shiu University, Kaohsiung, \\ Taiwan. E-mail: yjjou0506@yahoo.com.tw
}

Received: September 22, 2014 Accepted: October 25, 2014 Online Published: December 17, 2014

doi:10.5539/elt.v8n1p180 URL: http://dx.doi.org/10.5539/elt.v8n1p180

\begin{abstract}
Reading, whether the reader's First language, L1 or Second language, L2, is a cognitive enterprise, and it can be treated as a result of the interaction among the reader, the text, and the context. Metacognitive strategies refer to the behaviours applied by learners to plan, arrange, and evaluate their learning. This study aimed to investigate college students' use of metacognitive reading strategies in their first language (Chinese) and second language (English) while reading academic materials. The participants were technological university students in southern Taiwan. The Metacognitive Reading Strategies Questionnaire (MRSQ) was applied to investigate learners' use of metacognitive reading strategies in terms of analytic reading strategies and pragmatic reading Strategies in L1 and L2 reading. The results revealed that students used both analytic strategies and pragmatic strategies more frequently when they read L1 rather than L2 in academic articles. Though students tend to transfer their metacognitive reading strategies from L1 to L2, several strategies still showed significant differences in usage between reading L1 and L2. It hopes to shed light on the importance of Metacognitive reading strategies in language learning, and guide language learners in applying the strategies wisely and effectively.
\end{abstract}

Keywords: metacognition, metacognitive reading strategies

\section{Introduction}

Reading is referred as a decoding process for the purpose of extraction of meaning from written texts (McDonell, 2003). Whether in L1 or L2 context, reading includes readers, texts, and the interaction between readers and texts (Seng \& Fatimah, 2006) and all the activities are defined to as reading strategies or reading skills. Readers are required to use their prior knowledge, culture background, and skilled readers typically know how to identify the strategies they use and what kinds of strategies they use in certain conditions (Carrel, 1988; Pritchard, 1990). The awareness and monitoring in learning is often defined to in the literature as "Metacognition". More and more studies have focused on the significant role of metacognitive strategies in reading (Lengkanawati, 2004; Oxford, 1990; Phakiti, 2003; Taraban, Rynearson, \& Kerr, 2004). Metacognitive strategies refer to the behaviours applied by learners to plan, arrange, and evaluate their learning (Oxford, 1990). The awareness and use of these strategies is regarded as one of the significant elements in upgrading reading comprehension and successful learning (Alexander \& Jetton, 2000). In Taiwan, Chinese is the native and first language while English is the second language which is taught from elementary school up to high school. In comparison to the familiarity in the students' use of Chinese, the language which the students grew up with and has been practicing in everyday lives, most students' English learning experiences and usage focus only on the preparation for examinations.

Consequently, the exam-oriented L2 learning process deprives or neglects some learning strategies or experiences adopted in L1. In the past decades, many studies emphasized the importance of using of metacognitive strategies in reading (Brown, 1980; Cubukcu, 2008; Oxford, 1990), but limited literature focused on the differences in learners' application of metacognitive reading strategies in L1 and L2 reading. This study will address the application of metacognitive reading strategies by technological university students in southern Taiwan when they read academic materials in their first language Chinese, and in second language, English. The research questions are:

1) What metacognitive reading strategies do technological university students use in comprehending academic reading texts in Chinese (L1) and English (L2)? 
2) What are the similarities and differences between the application of metacognitive reading strategies in L1 and L2 academic reading among technological university students?

\section{Literature Reviw}

\subsection{L1 and L2 Reading}

Reading, whether in L1 or L2, is a cognitive enterprise; however, comparing the reading activities in L1 and L2 reading, Singhal (1998) stated that "reading in a second language was often viewed as a slower version of doing the same task in the native language. Such comparisons, however, imply that second language tasks are mapping tasks - that is, replacing one mode of behavior with another." Readers are inclined to apply the strategies they are familiar with in reading their native language (L1) to second or foreign languages (L2) reading. Singhal (1998) discussed the differences and similarities of L1 and L2 reading in terms of three cultural differences: content (background knowledge) schema, formal (textual) schema, and linguistic (language) schema. Enright, Grabe, Koda, Mosenthal, Mulcahy-Ernt, and Schedl (2000) described that L2 reading differs from L1 reading in three ways: firstly, L2 readers establish prior L1 reading experience; secondly, learners' reading processes are cross-linguistic, involving two or more languages; thirdly, the reading instruction usually starts before adequate oral proficiency in the target language has developed.

Chinese, the native language (L1) for most participants, is a logographic language, which is very different from English (L2), an alphabetical language. The characters of the Chinese language are independent from how it sounds. Actually, Parry (1996) stated that the relationship between the analytical characteristic of the Chinese writing system and the way Chinese has been taught could influence Chinese reader's approach in reading other languages, such as English. Scholars revealed that if the reading process is going through linear stages, decoding from letters to words to sentences, L2 readers might not be able to transfer these L1 strategies to L2 reading as it mostly depends on the readers' linguistic knowledge; however, there is still a gap between readers' knowledge of L1 and L2 (Kong, 2006).

\subsection{Metacognition in Reading}

Metacognition was first introduced by Flavell (1976), and defined as one's ability to understand, control, and manipulate his own cognitive process to maximize learning. Flavell (1979) described the process of cognitive monitoring as occurring through the actions and interactions of four interrelated phenomena: metacognitive knowledge, metacognitive experiences, goals (or tasks), and actions (or strategies). In terms of metacognitve knowledge, Wenden (1998) underscores its important role in the self-regulation of learning as language learners plan, monitor, and evaluate their learning. It is believed that metacognition is basically essential in various aspects of language learning, such as oral, reading, writing, and language acquisition. As metacognition relates to reading process and self-control mechanism for monitoring and enhancing comprehension, studies proved that it was the significant component in L1 as well as L2 reading (Guo \& Roehrig, 2011; Sheorey \& Mokhtari, 2001).

Actually, the application of metacognitive strategies has been regarded as one of the sufficient elements in successful language learning. It involves various processes such as planning, prioritizing, setting goals, and self-management (Hismanoglu, 2000). According to O'Malley and Chamot (1989), the major obstacle for successful language learning is that learners do not apply the learning strategies effectively. Dreyer (1998) pointed out the reason resulting in the unskilled or low reading comprehension was that the students' lack the awareness of reading strategy knowledge needed to successfully comprehend expository texts. In Al Melhi's study (Al Melhi, 2000), he indicated the skilled readers reported of their using global and reading strategies, metacognitive awareness while less skilled readers were lack of using them, and he also confirmed that the training of metacognitive language strategies help language learners improve their listening and reading proficiency.

Several instruments have been designed by scholars to investigate learners' application of metacognitive reading strategies. For instance, the Survey of Reading Strategies (SORS) was designed by Sheorey and Mokhtari (2001) to investigate the application of metacognitive reading strategies in reading academic materials. It was used to measure if there are any differences between English as the second language (ESL) students and English native students in their perceived strategies used while reading academic materials, and if there are any differences between male and female ESL students and English native students, respectively. The result revealed that ESL students used more strategies than the English native students and there was no significant difference in the strategies used between female and male students. Additionally, in order to investigate college students' reading strategies, Wade, Trathen, and Schraw (1990) recruited some volunteers who read a passage followed by a recall test. Participants were asked to write down the retrospective report of their reading strategies. After collecting the data, they identified 14 strategies and divided them into "three tactics". The first type was text-noting tactics, 
including highlighting, underlining, circling, copying key words, phrases or sentences, paraphrasing in notes, outlining and diagramming. The second one was mental learning tactics, including rote learning of specific information, mental integration, relating information to background knowledge, imaging, visualizing, self-questioning and self-testing. The third type was reading tactics, which included reading only, skimming, reading slowly, and re-reading selected text (Trathen \& Schraw, 1990). Based on the above related studies, the Metacognitive Reading Strategies Questionnaire (MRSQ) was developed by Taraban, Rynearson and Kerr (2004), particularly designed for assessing college students' use of the strategies for reading, and it was applied in this study. The questionnaire comprised analytic-cognitive and pragmatic-behavioral components. The analytic-cognitive component aimed to assess student's efforts to comprehend a text using different strategies which included rote learning of specific information, mental integration, relating information to background knowledge, imaging, visualizing, self-questioning, and self-testing. The pragmatic-behavioral component assessed students' studying and academic performance, which included the strategies such as noting, highlighting, underlining, read more, and re-read.

\section{Research Design}

\subsection{Participants}

The Participants of this study are technological university students in south Taiwan. They are students in the freshman English classes of the researcher. There were 174 students participating in this study. However, after eliminating cases such as missing answers and incomplete answers either in the Chinese or English part of the questionnaire, the total number of the cases used for this study is $146(\mathrm{n}=146)$, including 66 males $(\mathrm{n}=66,45 \%)$ and 80 females $(\mathrm{n}=80,54 \%)$. The students consented to the use of their response for research purposes and completed the questionnaire anonymously. As they were taking the Chinese (L1) and English (L2) courses at the same time in their first year of university, it was considered to be more appropriate to evaluate their application of metacognitive reading strategies.

\subsection{Instruments}

The Metacognitive Reading Strategies Questionnaire (MRSQ) (Taraban, Rynearson, \& Kerr, 2004) was applied to investigate learners' use of metacognitive reading strategies in reading English and Chinese. The questionnaire for investigating learners' strategies in English was also translated into Chinese to make sure that there will not be any misunderstanding by the students when answering the questionnaire. They were asked to respond to items using a 5-point Likert scale ranking "strong agree", "agree", "no opinion", "disagree" and "strongly disagree". An informative cover page assured participants that this was not a test with right or wrong answers, and their forthright and honest responses were expected and appreciated. The questionnaire includes twenty-two statements, and they are categorized into two aspects, analytic and pragmatic, for further investigation. In order to avoid confusion or questionnaire fatigue, the questionnaire for evaluating metacognitive reading strategies in English was conducted in the first week while the questionnaire for investigating the Chinese was applied in the second week.

\subsection{Data Analysis}

The MRSQ was divided into two categories: analytic and pragmatic reading strategies. The software package Statistical Package for Social Sciences (SPSS) was applied to analyze the relative frequency, mean and standard deviation of the students' answers in MRSQ. Finally, the differences in applying metacognitive strategies in reading Chinese and English were surveyed as well. In order to measure the internal consistency in English (L2) and Chinese (L1) questionnaire, Cronbach Alphas for the Analytic and Pragmatic subscales of MRSQ was displayed in Table1.

Table 1. Cronbach alphas for MRSQ in English (L2) and Chinese (L1) reading

\begin{tabular}{lll}
\hline & Items & Alpha \\
\hline Analytic- English & 16 & .855 \\
Analytic- Chinese & 16 & .866 \\
Pragmatic- English & 6 & .766 \\
Pragmatic- Chinese & 6 & .795 \\
\hline
\end{tabular}


According to above data, we can conclude the reliability for both subscales for investigating English and Chinese reading strategies illustrated good estimates of scale's internal consistency.

\section{Results and Discussion}

4.1 The Application of Analytic Reading Strategies in English (L2) and Chinese (L1) Reading

Table 2. The mean (M), and standard error (SE) of applying analytic reading strategies in English (L2) and Chinese(L1) reading

\begin{tabular}{|c|c|c|c|c|}
\hline & $\begin{array}{l}\mathrm{M} \\
(\mathrm{L} 2)\end{array}$ & $\begin{array}{l}\text { M } \\
(\mathrm{L} 1)\end{array}$ & $\begin{array}{l}\mathrm{SE} \\
(\mathrm{L} 2)\end{array}$ & $\begin{array}{l}\mathrm{SE} \\
(\mathrm{L} 1)\end{array}$ \\
\hline $\begin{array}{l}\text { 1. Evaluate: evaluate texts to decide if it contributes to my knowledge of } \\
\text { the texts }\end{array}$ & 3.31 & 3.53 & .883 & .888 \\
\hline 2. Anticipate: anticipate how I will use the knowledge gaining from the text & 3.01 & 3.46 & .932 & .856 \\
\hline 3. Draw: draw on my knowledge of the topic to help understand the content & 2.77 & 2.66 & 1.264 & 1.052 \\
\hline $\begin{array}{l}\text { 4. Back: reconsider my background knowledge about the topic, based on } \\
\text { the content }\end{array}$ & 3.23 & 3.47 & .887 & .790 \\
\hline 5. Revise: revise prior questions about the topic, based on the content & 3.27 & 3.44 & .979 & .871 \\
\hline $\begin{array}{l}\text { 6.Consider: consider possible interpretations to decide if understanding the } \\
\text { content }\end{array}$ & 3.42 & 3.76 & .945 & .920 \\
\hline 7. Distinguish: distinguish already-known information and new information & 3.28 & 3.60 & 1.022 & .907 \\
\hline $\begin{array}{l}\text { 8. Infer: infer the information from the text while facing difficulties in } \\
\text { understanding }\end{array}$ & 3.52 & 3.80 & 1.045 & .922 \\
\hline 9. Reading goals: evaluate if materials are relevant to reading goals & 3.14 & 3.54 & 1.083 & .918 \\
\hline 10. Search: search out information relevant to reading goals & 3.08 & 3.25 & 1.139 & .995 \\
\hline 11. Present later: anticipate information that will be presented later & 3.05 & 3.43 & 1.075 & .909 \\
\hline 12. Meaning: try to determine the meaning of unknown but critical words & 3.32 & 3.42 & 1.022 & .877 \\
\hline 13. Current information: check if I had anticipated the current information & 3.04 & 3.27 & .886 & .875 \\
\hline $\begin{array}{l}\text { 14. Strengths: exploit my personal strengths to better understand the } \\
\text { contents }\end{array}$ & 3.62 & 3.71 & .998 & .984 \\
\hline $\begin{array}{l}\text { 15. Visualize descriptions: visualize descriptions to better understand the } \\
\text { text }\end{array}$ & 2.95 & 2.90 & 1.155 & 1.100 \\
\hline 16. Hard: note how hard or easy a text to read & 2.55 & 2.77 & 1.077 & 1.017 \\
\hline
\end{tabular}

From Table 2, the finding illustrated that the most frequently used analytic reading strategies for both L2 and L1 were: Consider (L2M=3.42, L1M=3.76), Infer ( $\mathrm{L} 2 \mathrm{M}=3.52, \mathrm{~L} 1 \mathrm{M}=3.80$ ), and strengths ( $\mathrm{L} 2 \mathrm{M}=3.62, \mathrm{~L} 1 \mathrm{M}=3.71$ ). It implied that large percentages of learners were able to consider other interpretations to help their understanding (Consider), try to infer the information from the text (Infer), and exploit strengths to understand the text (Strengths). The result was partly correspondent with Kong's research as she concluded that the most often used strategies for L1 and L2 were prior knowledge - to utilize one's knowledge of the text structure, and prior content knowledge in figuring out the authors' points of view in texts (Kong, 2006).

On the other hand, the results showed most students are lack of experiences in the usage of strategies like Hard, Drawing, and Visualizing descriptions to understand the topic or text in their L1 and L2 reading. They seldom note down the level of difficulty of the text (Hard), draw on my knowledge of the topic to help understand the content (Draw) and visualize concepts to better understand text (Visualize description). Albert Einstein said," If I can't picture it, I can't understand it", and it is definitely beneficial and essential to process and internalize the new information by listing, mapping, and drawing etc. However, it consists of several complicated steps to visualize the information, such as data transformation, visual mapping, and interactive framing (Lima, 2011). Obviously, our learners required further instruction and practices in mastering these strategies in language learning. 
Moreover, Table 2 also showed that students reported using most of the analytic reading strategies more frequently while reading Chinese than English. The result is relatively predictable since the nature of analytic reading strategies requires more cognitive skills. For most of the L2 learners, they might have linguistic knowledge problems, such as vocabulary, sentence structure, and even cultural barrier, to cause their hesitation in applying strategies. Enright et al.(2000) indicated several factors distinguishing L2 readers from L1, including transfer of L1 reading skills and strategies, facilitation in discovering structural similarity in L1 and L2, cross linguistic interactions during L2 reading, and processing constraints imposed by limited linguistic knowledge. Yet, it is interesting to find that the Draw and Visualize descriptions are the two strategies that students showed they used more in L2 than L1. It seems that the students might create their own ways of using drawing to help in their reading comprehension. As they are two effective strategies to improve the reading comprehension, teachers may consider using more supplements, such as pictures, video to inspire students' understanding in language classroom.

\subsection{Differences in Applying Analytic Reading Strategies for English and Chinese Reading}

Table 3. Paired sample t-tests of applying analytic reading strategies in English (E) and Chinese (C) reading

\begin{tabular}{llllll}
\hline & $\mathrm{M}$ & $\mathrm{SD}$ & $\mathrm{SE}$ & $\mathrm{t}$ (2-tailed) & Sig. \\
\hline 1. Evaluate (E2/C1) & -.219 & 1.073 & .089 & -2.468 & .015 \\
2. Anticipate. (E2/C2) & -.445 & 1.121 & .093 & -4.801 & .000 \\
3. Draw (E3/C3) & .110 & 1.405 & .116 & .942 & .348 \\
4. Back (E4/C4) & -.240 & 1.019 & .084 & -2.842 & .005 \\
5. Revise (E5/C5) & -.164 & 1.139 & .094 & -1.744 & .083 \\
6. Consider (E6/C6) & -.342 & 1.171 & .097 & -3.533 & .001 \\
7. Distinguish (E7/C8) & -.315 & 1.167 & .097 & -3.262 & .001 \\
8. Infer (E8/C8) & -.281 & 1.149 & .095 & -2.953 & .004 \\
9. Reading goals (E9/C9) & -.397 & 1.092 & .090 & -4.395 & .000 \\
10. Search (E10/C10) & -.178 & 1.408 & .117 & -1.528 & .129 \\
11. Present later (E11/C11) & -.377 & 1.140 & .094 & -3.995 & .000 \\
12. Meaning (E12/C12) & -.103 & 1.167 & .097 & -1.064 & .289 \\
13. Current information (E13/C14) & -.233 & 1.181 & .098 & -2.384 & .018 \\
14. Strengths (E14/C14) & -.089 & 1.180 & .098 & -.912 & .363 \\
15. Visualize descriptions (E15/C15) & .048 & 1.245 & .103 & .465 & .642 \\
16. Hard (E16/C16) & -.219 & 1.321 & .109 & -2.005 & .047 \\
\hline
\end{tabular}

The result in Table 3 indicated ten (Evaluate, Anticipate, Back, Consider, Distinguish, Infer, Reading goals, Present later, Current information, Visualize descriptions) out of sixteen analytic reading strategies showed significant differences in reading English and Chinese, but not for strategies like Draw, Revise, Search, Meaning, Strengths, and Visualize descriptions. If we compare with the result from Table 2, we can find among these 10 strategies showing the significant differences, Consider (P6), Distinguish (P8), and evaluate (P1) reported the most frequently used analytic reading strategies, whereas Hard (P16) is the least frequently used strategy. The result is partly correspondent with the Kong's (2006) research of the strategies employed between the Chinese and English texts, and there are some similarities: (1) using text structure, (2) invoking prior knowledge, and (3) evaluating what they read in reading both languages. Additionally, for the strategy of noting how hard or easy a text is, it can benefit students to sort out the materials they have read, and it seems to be neglected by participants in both English and Chinese reading.

It implies that most students can consider other possible interpretations to understand the text, infer the information from the text, and evaluate if the text contributes to one's knowledge; moreover, they tend to use more of these strategies in reading L1 than L2. For university students, Chinese characters do not seem to be a problem for them; it is quite comfortable for them to apply the various strategies in academic reading. However, 
most English teaching and learning in Taiwan focus on a bottom-up model, which means that their learning process starts from memorizing vocabularies, and followed by phrases, sentences, paragraphs, and articles etc. In this researcher's class, many students indicated that they spent most of the time memorizing vocabularies and phrases while preparing English exams and other learning activities. Obviously, the uses of reading strategies such as infer, evaluate, and anticipate etc. is relatively neglected in L2 reading. It seems that although learners have been familiar with using these strategies in their L1 reading, yet they may need some practices in applying the same strategies in L2 reading. Especially for beginners or low-achievement readers, they may need encouragement to make some efforts to master the application of these strategies.

\subsection{The Application of Pragmatic Reading Strategies in English (L2) and Chinese (L1) Reading}

Table 4. The mean (M), and standard error (SE) of applying pragmatic reading strategies in English (L2) and Chinese (L1) reading

\begin{tabular}{|c|c|c|c|c|}
\hline & $\begin{array}{l}\mathrm{M} \\
(\mathrm{L} 2)\end{array}$ & $\begin{array}{l}\mathrm{M} \\
(\mathrm{L} 1)\end{array}$ & $\begin{array}{l}\mathrm{SE} \\
(\mathrm{L} 2)\end{array}$ & $\begin{array}{l}\text { SE } \\
(\mathrm{L} 1)\end{array}$ \\
\hline 17. Notes: make notes while reading to remen & 2.62 & 2.89 & 1.158 & 1.102 \\
\hline $\begin{array}{l}\text { 18. Highlight: underline and highlight information to find it more } \\
\text { easier later on }\end{array}$ & 3.29 & 3.33 & 1.134 & 1.025 \\
\hline $\begin{array}{l}\text { 19. Margin: write questions and notes in the margin for better } \\
\text { understanding }\end{array}$ & 2.97 & 3.05 & 1.135 & 1.081 \\
\hline 20. Underline: underline while reading to remember information & 3.48 & 3.52 & 1.071 & .977 \\
\hline 21. Read more: read more than once to remember information & 3.51 & 3.71 & 1.032 & .961 \\
\hline 22. Re-read: Re-read when having difficulty comprehending text & 3.73 & 4.00 & 1.073 & .961 \\
\hline
\end{tabular}

The top two frequently used pragmatic reading strategies were Re-read, Read more for L2 reading, and the same result was also showed in L1 reading. As mentioned, vocabulary does not seem to cause many problems for adult L1 readers; yet, one of the major obstacles in reading academic Chinese articles comes from the interpretation of classical Chinese. Even when every word is recognized, students might have hard time in understanding some sentences and content owing to the different meanings of Chinese characters and usages of sentence structure. Re-read and Read more help the learners to trigger their previous reading experiences and relate those experiences to their current reading. Comparatively, while reading English, limited vocabulary, sentence structure, and cultural barrier are the barriers in L2 reading for most learners. While Re-read and Read more seems to be the instinctive and spontaneous response to deal with the reading obstacles, studies showed that it might not seem to give immediate benefit in improving reading comprehension (Vianty, 2007). Also, the strategy of Note, making notes while reading to remember the information, was reported as least frequently used both in L1 and L2 reading. Actually, taking notes is one of the effective strategies to enhance learning outcome. Learners are encouraged to take notes for summarizing, organizing information, and writing down their feedback of the articles. Especially in L2 learning, it can also help learners to memorize pronunciation and intonation in listening classroom. However, as more and more "user friendly" PPT and supporting supplements are provided in the classroom, students can grasp the materials instantly without taking notes. They even use their cell phones to take photographs of everything which previously would have entailed them to take notes. It can be predicted that learners will rely more and more on digital devices in dealing with their learning activities.

In addition, students were inclined to apply pragmatic reading strategies more often in reading L1 rather than L2. Logically, students might encounter difficulties in understanding the words or sentences in L2, and without understanding the content, it would surely prevent them from underlining or highlighting the main ideas or important information as well as writing notes or questions in the margin. Actually, the application of pragmatic strategies strongly relates to students' learning motivation in solving the problems. The finding was different from Vianty's study (2007) as it showed learners reported more frequently use of the pragmatic reading strategies in L2 (English) than L1 (Bahasa Indonesia) reading. 


\subsection{Differences in Applying Pragmatic Reading Strategies for English and Chinese Reading}

Table 5. Paired sample t-tests of applying pragmatic reading strategies in English (E) and Chinese (C) reading

\begin{tabular}{llllll}
\hline & $\mathrm{M}$ & $\mathrm{SD}$ & $\mathrm{SE}$ & $\mathrm{t}$ (2-tailed) & Sig. \\
\hline 17. Note(E17/C17) & -.274 & 1.426 & .118 & -2.321 & .022 \\
18. Highlight (E17/C17) & -.034 & 1.098 & .091 & -.377 & .707 \\
19. Margin(E17/C17) & -.089 & 1.264 & .105 & -.851 & .396 \\
20. Underline(E17/C17) & -.041 & 1.113 & .092 & -.446 & .656 \\
21. Read more(E17/C17) & -.205 & 1.138 & .094 & -2.181 & .031 \\
22. Re-read(E17/C17) & -.274 & 1.218 & .101 & -2.718 & .007 \\
\hline
\end{tabular}

For the differences of applying pragmatic reading strategies for English and Chinese Reading, the result indicated that the strategies of Re-read, Read more, and Note showed that there are significant differences, but not for the strategies of Highlight, Margin, and Underline. It seems that the application of pragmatic strategies is strongly related to learners' learning motivation or language proficiency. It is quite natural for readers to re-read the text in their native language to gain the information clearly. Yet, for low-achieving L2 learners, they might need to understand the text before they can take notes and build up confidence to re-read or read more. Weisnstein and Meyer (1991) declared the strategies such as highlighting and underlining could be treated as important repetition strategies for any readers in terms of information-processing. They can help learners review important information and create further opportunities to learn and save information as long-term memory. In other words, these strategies are crucial for L1 and L2 learners to remember information, especial dealing with assignment and tests.

\section{Conclusion}

Reading in both L1 and L2 involves the interaction of many variables, and readers use mental activities to develop reading skills or strategies to construct meaning from the text. This study investigated the technological university students' application of metacognitive reading strategies in Chinese (L1) and English (L2) academic reading, and whether there were any significant differences between them. The result revealed that for analytic reading strategies, strengths, Infer, Consider were reported as the most frequently used strategies in L1 and L2 reading while Read more, and Re-read are used more often for pragmatic strategies. The least frequently used strategies were Hard, Drawing, Visualizing description for analytic strategies, and Noting for pragmatic strategies in both L1 and L2 reading. Moreover, students reported that they used both analytic and pragmatic strategies more frequently when they read Chinese rather than English in academic articles. Reading requires knowledge of content, formal, and linguistic schema. When L2 readers are not familiar with culturally based knowledge or do not possess the same linguistic base as the L1 reader, they will encounter difficulties (Hameed, 2008). It requires the coordination of analytic and pragmatic strategies effectively to enhance the learning outcome in L1 and L2 reading. It is essential for teachers not only to remind and enforce the strategies they have been familiar with in L1 to apply in L2 reading, but also introduce the new strategies, such as visualize description to improve their reading comprehension. As previous studies suggested that the reading comprehension can be enhanced through systematic instruction of metecognitive reading strategies (Cubukcu, 2008), instructors might consider designing the specific training programs to meet the individual's needs for improving the learning outcome. Besides that, learning motivation is certainly another important factor influencing the application of reading strategies; how to encourage the low-achieving learners to develop the reading strategies systemically and appropriately challenges all the language educators. Furthermore, with the limitation of the small sample used in this research, it might not be able to represent the real situation. We hope to repeat the survey with larger samples and conduct individual interview for more detailed investigation. Future study will also evaluate if there is any correlation between learners' application of metacognitive reading strategies and their learning performance in L1 and L2 academic reading.

\section{References}

Alexander, P. A., \& Jetton, T. L. (2000). Learning from text: A multidimensional and developmental perspective. In M. L. Kamil, P. Mosenthal, P. D. Pearson, \& R. Barr (Eds.), Handbook of reading research (Vol. 3, pp. 285-310). Mahwah, NJ: Lawrence Erlbaum Associates. 
Al-Melhi, A. M. (2000). Analysis of Saudi college students, reported and actual strategies along with their metacognitive awareness as they read in English as a foreign language. Dissertation Abstracts International: The Humanities and Social Sciences, 60(7).

Brown, A. L. (1980). Metacognitive development and reading. In R. J. Spiro, B. C. Bruce, \& W. F. Brewer (Eds.), Theoretical issues in reading comprehension (pp. 453-481). Hillsdale, NJ: Erlbaum.

Carrell, P. L. (1988). Interactive text processing: Implications for ESL/second language reading classrooms. In P. L. Carrell, J. Devine, \& D. E. Eskey (Eds.), Interactive Approaches to Second Language Reading (pp.239-259). Cambridge University Press.

Cubukcu, F. (2008). How to enhanced reading comprehension through metacognitive strategies, The Journal of International Social Research, I(2). Retrieved January 2, 2012, from http://www.sosyalarastirmalar.com/ cilt1/sayi2/sayi2pdf/cubukcu_feryal.pdf

Dreyer, C. (1998). Improving students' reading comprehension by means of strategy instruction. Journal for Language Teaching, 31, 18-29.

Enright, M. K., Grabe, W., Koda, K., Mosenthal, P., Mulcahy-Ernt, P., \& Schedl. M. (2000). TOEFL 2000 Reading Framework: A Working Paper. TOEFL monograph series. Retrieved October 10, 2012, from http://www.toefl.org

Flavell, J. H. (1976). Metacognitive aspects of problem solving. In L. B. Resnick (Ed.), The nature of intelligence (pp.231-236). Hillsdale, NJ: Erlbaum.

Flavell, J. H. (1979). Metacognition and cognitive monitoring: A new area of cognitive-developmental inquiry. American Psychologist, 34, 906-911.

Guo, Y., \& Roehrig, A. D. (2011). General versus second language specific knowledge in the English reading comprehension of Chinese-speaking learners. Reading in a Foreign Language, 23(1), $42-64$.

Hameed, H. T. (2008). A comparison of L1 and L2 reading: Cultural differences and schema. Journal of Research Diyala humanity, 28, 244-272.

Hismanoglu, M. (2000). Language learning strategies in foreign language learning and teaching. The Internet TESL Journal, 6(8). Retrieved August 3, 2014, from http://iteslj.org/Articles/Hismanoglu-Strategies.html

Kong, A. (2006). Connections between L1 and 12 readings: Reading strategies used by four Chinese adult readers. The Reading Matrix, 6(2), 19-45.

Lengkanawati, N. S. (2004). How learners from different cultural backgrounds learn a foreign language. Asian EFL Journal, 6(1). Retrieved August 3, 2014, from http://www.asian-efl-journal.com/04_nsl.php

Lima, M. (2011). Information Visualization Framework. Retrieved from http://www.visualcomplexity.com/ $\mathrm{vc} / \mathrm{blog} / ? \mathrm{p}=1076$

McDonell, T. B. (2003). The effects of text presentation: Linear and hypertext On English language learners. IT Forum paper, School of Education, New York University.

O’Malley, J. M., \& Chamot, A. U. (1989). Learning strategies in second language acquisition. Cambridge: Cambridge University Press.

Oxford, R. (1990). Language learning strategies: What every teacher should know. Boston: Heinle \& Heinle.

Parry, K. (1996). Culture, Literacy, and L2 Reading. TESOL Quarterly, 30(4), 665-692.

Phakiti, A. (2003). A closer look at the relationship of cognitive and metacognitive strategy use to EFL reading achievement test performance. Language Testing, 20(1), 26-56.

Pritchard, R. (1990). The effects of cultural schemata on reading processing strategies. Reading Research Quarterly, 25(4), 273-295.

Seng, G. H., \& Fatimah, H. (2006). Use of L1 in L2 reading comprehension among tertiary ESL. Reading in a Foreign Language, 18(1), 29-54.

Sheorey, R., \& Mokhtari, K. (2001). Differences in the metacognitive awareness of reading strategies between native and nonnative readers. System: Journal of Applied Linguistics and Educational Technology, 29, 431-449.

Singhal, M. (1998). A comparison of L1 and L2 reading: Cultural differences and schema. The Internet TESL Journal, 4(10). Retrieved July 28, 2014, from http://iteslj.org/Articles/Singhal-ReadingL1L2.html 
Taraban, R., Rynearson, K., \& Kerr, M. S. (2004). Analytic and pragmatic factors in college students' metacognitive reading strategies. Reading Psychology, 25(2), 67-81.

Vianty, M. (2007). The comparison of students' use of metacognitive reading strategies between reading in Bahasa Indonesia and in English. International Education Journal, 8(2), 449-460.

Wade, S. E., Trathen, W., \& Schraw, G. (1990). An analysis of spontaneous study strategies. Reading Research Quarterly, 25(2), 147-166.

Weinstein, C. F., \& Meyer, D. K. (1991). Cognitive learning strategies. In R. J. Menges, \& M. D. Svinicki (Eds.), College teaching: From theory to practice (pp. 15-26). New Directions for Teaching and Learning, no. 45. San Francisco: Jossey-Bass.

Wenden, A. L. (1998). Metacognitive knowledge and language learning. Applied Linguistics, 19(4), 515-537.

\section{Copyrights}

Copyright for this article is retained by the author(s), with first publication rights granted to the journal.

This is an open-access article distributed under the terms and conditions of the Creative Commons Attribution license (http://creativecommons.org/licenses/by/3.0/). 